\title{
Diclofenac epolamine topical patch relieves pain associated with ankle sprain
}

\author{
This article was published in the following Dove Press journal: \\ Journal of Pain Research \\ 24 February 20II \\ Number of times this article has been viewed
}

\author{
David R Lionberger' \\ Eric Joussellin ${ }^{2}$ \\ Arturo Lanzarotti ${ }^{3}$ \\ Jillmarie Yanchick ${ }^{4}$ \\ Merrell Magelli ${ }^{5}$ \\ 'Southwest Orthopedic Group, \\ LLP, Houston, Texas, USA; ${ }^{2}$ Institut \\ National du Sport, Paris, France; \\ ${ }^{3}$ Institut Biochimique SA, Pambio- \\ Noranco, Switzerland; ${ }^{4}$ Alpharma \\ Pharmaceuticals LLC, a wholly owned \\ subsidiary of King Pharmaceuticals ${ }^{\circledR}$, \\ Inc, Piscataway, New Jersey, USA; \\ ${ }^{5} \mathrm{GT} x$, Inc, Memphis, Tennessee, USA
}

Correspondence: David R Lionberger Southwest Orthopedic Group, LLP 6550 Fannin Street

Houston, TX 77030, USA

Tel +l 7I33334100

Fax +17133334101

Email dlionberger@mysurgeon.com
Background: Sports-related injuries, such as sprains and strains, commonly occur during exercise and athletic events. Current therapy includes nonsteroidal anti-inflammatory drugs (NSAIDs), which have a high incidence of upper gastrointestinal side effects. The present study assessed the efficacy and safety of the diclofenac epolamine topical patch (DETP, 1.3\%), a topical NSAID for the treatment of acute minor sprains and strains.

Methods: This multicenter, randomized, placebo-controlled clinical study enrolled adult patients ( $n=134)$ with acute ankle pain (due to a minor sprain) occurring less than 48 hours prior to entering the study. Patients were treated with either the DETP or a placebo topical patch daily for seven days. Pain intensity was evaluated during the first six hours after application of the patch, and on treatment days 1, 2, 3, and 7.

Results: Patients treated with the DETP experienced a significantly greater reduction in pain associated with their ankle injury compared with placebo, beginning four hours after the first patch application $(P=0.02)$. The DETP was well tolerated and was comparable with placebo in terms of safety.

Conclusion: Overall, the results of this study demonstrate that the DETP is an effective analgesic for local treatment of pain in mild acute ankle sprain.

Keywords: soft tissue injury, acute pain, visual analog scale, efficacy, tolerability

\section{Introduction}

Sports and other exercise-related activities are a major cause of soft tissue and joint injuries, resulting in sprains, strains, and contusions. The ankle is frequently traumatized during sports activities, which account for an estimated $20 \%$ of all sports-related injuries. ${ }^{1}$ Nonsurgical treatment of ankle sprains is predicated on prevention of further injury, reduction of inflammation, and management of pain. ${ }^{1,2}$ Traditional oral nonsteroidal anti-inflammatory drugs (NSAIDs) are used to provide analgesia and relief from inflammation in patients with acute ankle sprain. However, use of these drugs can lead to adverse reactions associated with the upper gastrointestinal tract, and renal, cardiovascular, and respiratory systems, mainly by reduction of systemic prostaglandin production through direct inhibition of cyclooxygenase enzymes. ${ }^{3}$

In contrast, topical NSAID preparations permit direct application of drug at the site of pain. Direct application results in continuous and localized drug delivery to the pain site, while minimizing systemic levels of drug ( $0.2 \%$ to $8 \%$ of the oral equivalent), thereby reducing the local inflammatory reaction while ostensibly avoiding systemic adverse events. ${ }^{4}$ The diclofenac epolamine topical patch (DETP) is a topical NSAID patch with demonstrated analgesic activity. ${ }^{5}$ Prior studies have shown that topical 
diclofenac can be transported across the skin into the injured site, maintaining measurable levels of the drug in synovial fluid, while providing a constant plasma level of diclofenac for up to 12 hours. . $^{6,7}$

Because the efficacy of the DETP has been demonstrated in patients treated for minor sports injuries in prior studies, ${ }^{8-10}$ this clinical trial was performed to establish its efficacy using a more rigorous methodology. The aim of this placebo-controlled clinical study was to demonstrate the efficacy and tolerability of the DETP applied once per day for seven days in the treatment of minor acute ankle sprain. Partial results of this study have been published previously in French. ${ }^{10}$

\section{Methods}

This Phase III, multicenter, double-blind, randomized, parallel-group, placebo-controlled trial, assessed the efficacy and tolerability of the DETP in the treatment of minor ankle sprain. The study was performed at 19 French health centers and included 24 physician investigators. The study protocol was approved by the French Ethical Committee, and was conducted in accordance with the Declaration of Helsinki guidelines.

\section{Study population}

Male and female patients, aged 18-65 years, who sustained an ankle sprain $<48$ hours before study entry and had a pain score $\geq 50 \mathrm{~mm}$ on a $100 \mathrm{~mm}$ visual analog scale were included in this study if the injury justified use of a seven-day NSAID topical treatment. Patients were excluded from the study if the ankle sprain required orthopedic or surgical treatment, the sprain had been treated prior to study entry, they had been treated for other sprains within 1 week of the study, or if they had a history of recurrent sprains. Female patients who were pregnant, lactating, or of childbearing potential were excluded from this study. In addition, patients were excluded if they had: an allergy to aspirin, NSAIDs, or the excipients in the DETP; a history of skin allergy; or an open skin lesion within the injured area (eg, eczema, psoriasis). Finally, patients being treated by physiotherapy or an alternative medicine (eg, acupuncture, mesotherapy, homeopathy) or who had received oral or parenteral treatment with corticosteroids, NSAIDs, or aspirin seven days prior to study entry, or had received any analgesic within six hours of patient recruitment were also excluded. The study was discussed with each of the prospective patients, and those wishing to participate signed an informed consent form detailing the entire study.

\section{Study design}

After signing an informed consent, each study patient was randomly assigned, in blocks of four and in increasing order, a study number corresponding to the preassigned number on a packet of blinded test articles (ie, the DETP or placebo patch). All patients randomized to the active treatment received two boxes, each box containing five DETPs, sufficient for a seven-day treatment, with a surplus of three patches. The DETP contained diclofenac epolamine $1.3 \%$ in a patch measuring $10 \times 14 \mathrm{~cm}$. Patients who were randomized to the placebo group received two boxes, each containing five placebo patches. Placebo patches were identical in appearance and used the same formula as the active patch, without the active ingredient, diclofenac epolamine. Patients in both the DETP and placebo groups applied a single daily patch to the site of injury in the morning, for seven days. The patch was maintained by an elastic compression net bandage, and changed daily.

The application of ice or protective wrap was allowed in both groups and recorded. If necessary, the intake of paracetamol was authorized as a rescue medication three hours after the first application of a patch; the consumption in both groups was recorded. Paracetamol $\leq 2 \mathrm{~g}$ /day was allowed as rescue medication.

\section{Efficacy and safety variables}

The duration of treatment was seven days. The primary efficacy variable was spontaneous pain (pain on active mobilization), which was assessed by the patient on a $100 \mathrm{~mm}$ Huskisson-type visual analog scale ranging from $0=$ no pain to $100=$ severe pain. Spontaneous pain, derived from the patient diary, was evaluated at the following times: on day 0 at the first six hours after application of the initial patch and at $8 \mathrm{pm}$, on days 1 and 2 at $8 \mathrm{am}, 12 \mathrm{pm}$, and $8 \mathrm{pm}$, and on day 3 at $8 \mathrm{am}$. At the end of treatment, patients were considered "improved" and therapy efficient if the reduction in visual analog scale value between entry into the study and study termination was $\geq 20 \mathrm{~mm}$ or if the percentage change from baseline in visual analog scale value was $\geq 30 \%$. An approximately $30 \%$ improvement in pain score has been considered to be a clinically important difference in treating acute pain. ${ }^{11}$

Secondary efficacy variables included an evaluation of the analgesic effect, an assessment of the anti-inflammatory effect, and a patient assessment of treatment efficacy. The analgesic effect was assessed using the following four parameters: pain at rest according to a four-point verbal scale of $0=$ no pain, $1=$ slight pain, $2=$ medium pain, and 
3 = severe pain; pain on passive stretch and pain on pressure (external lateral ligament, front and medium fascicle) according to the same pain at rest scale; and possibility of single foot leaning on the affected foot according to a three-point scale of $0=$ hold possible without any pain, $1=$ hold possible but painful, and 2 = hold impossible. The anti-inflammatory effect was determined by assessing periarticular edema/swelling, which was evaluated by measuring, in $\mathrm{mm}$, the difference in circumference between the healthy and impaired ankle, using a measuring tape.

The safety measurements included an assessment of tolerability by the patient and physician, and a recording of adverse events. Each patient who completed the protocol was exposed continuously to one patch applied to the painful area, with patch renewal once daily for a period of one week. A global tolerability assessment was done on day 3 and day 7 by both the patient and physician. The assessments were conducted using a four-point verbal scale, where "none" indicated little tolerability and "excellent" indicated the highest levels of tolerability. The patient and physician assessments on general tolerability were reported at the end of treatment on a four-point scale of excellent, good, fair, and bad.

\section{Statistical analysis}

All patients who used a study patch were to be included in the intent-to-treat analysis. Patients who stopped treatment for reasons of "failure", "worsening", "healing", or "disappearance of symptoms" were part of the efficacy analysis, with data from the last observation carried forward.

Demographic and baseline characteristics were evaluated using Bonferroni's analysis. The measured parameter visual analog scale at the study visits was analyzed by a two-way analysis of variance (ANOVA) with factors for treatment group and time, and an ANOVA with one factor (time) within the groups. Edema, a secondary efficacy variable, was analyzed similarly. Categorical variables (ie, single foot leaning; pain on pressure, at rest, or on passive stretch; and assessments by patient and physician on efficacy and tolerability) were analyzed using the Mantel-Haenszel chi-square or Fisher's exact test.

Mean VAS scores were summarized at each patch application using a last observation carried forward (LOCF) method for imputing missing data. This procedure assumes that the subject's response would have been constant from the last observation to the next, or to the end of the trial. In general, this is thought to be a highly conservative approach that may underestimate therapeutic benefits in a longitudinal study, such as this one.
Safety analyses included all patients enrolled in the study, and compared the number of patients with specific adverse events, total adverse events, and dropout due to treatment intolerability between groups.

\section{Results}

A total of 134 patients were enrolled in the study by 24 investigators; 68 patients were randomized to the DETP group and 66 patients to the placebo group. All patients were included in the analysis of efficacy and safety (intent-totreat analysis). A total of 127 patients completed the study as planned; seven patients withdrew from the study before completion. These withdrawals were for pruritus, protocol violation, edema, or lack of efficacy.

The mean age was 33.3 years in the DETP group and 29.7 years in the placebo group (Table 1). Women in the placebo group were slightly younger than women in the DETP group $(P=0.1)$, with a lower body mass index $(23.6 \mathrm{~kg} /$ $\mathrm{m}^{2}$ DETP versus $21.1 \mathrm{~kg} / \mathrm{m}^{2}$ placebo, $P=0.05$ ). A specific analysis that adjusted for BMI was performed and showed that there were no statistically significant differences between the treatment groups related to BMI. There were no differences between groups for application of ice by the patients before enrollment. In addition, no significant differences were found in initial measurements of pain or periarticular edema between the two groups.

\section{Efficacy}

Patients in both treatment groups demonstrated a prominent decrease in mean visual analog scale values over time. However, in the DETP group the decrease in visual analog scale score from 66.9 on day 0 to 10.5 on day 7 was significantly greater compared with that in the placebo group, which decreased from 70.0 on day 0 to 18.4 on day $7(P=0.0008)$. Additional analyses revealed that the mean decrease in visual analog score measured four hours after the first application was two-fold greater for the DETP patients than for those given placebo $(P=0.02)$. The difference in relative change was significantly greater for the DETP group at each time point, with the exception of day 1 at the 8 am time point, as shown by the median change from baseline (see Figure 1).

The success/failure analysis, with success defined as a visual analog score reduction of $\geq 20 \mathrm{~mm}$ between the day 0 consultation and the last known value, demonstrated that the rate of success was significantly higher in the DETP group from four hours after the first application, and remained significant for six of the 10 measures until day 2 at the 8 pm time point. When success/failure was based on change in visual 
Table I Baseline characteristics of patients in both groups

\begin{tabular}{|c|c|c|c|}
\hline Characteristic & $\begin{array}{l}\text { DETP } \\
(n=68)\end{array}$ & $\begin{array}{l}\text { Placebo } \\
(n=66)\end{array}$ & $P$ value $^{\mathrm{a}}$ \\
\hline Age, mean (SD) & $33.3(13.9)$ & $29.7(11.6)$ & 0.1 \\
\hline Gender: male/female & $33 / 35$ & $39 / 27$ & 0.2 \\
\hline \multicolumn{4}{|l|}{ Weight: mean (SD) } \\
\hline Males & $75.4(11.0)$ & $77.7(19.2)$ & 0.5 \\
\hline Females & $62.8(12.6)$ & $57.1(9.2)$ & 0.05 \\
\hline \multicolumn{4}{|l|}{ Body mass index, mean (SD) } \\
\hline Males & $23.9(3.3)$ & $24.8(5.6)$ & 0.5 \\
\hline Females & $23.6(5.1)$ & $21.1(3.0)$ & 0.05 \\
\hline \multicolumn{4}{|l|}{ Ice application } \\
\hline No (\%) & $43(63.2)$ & $39(59.1)$ & 0.6 \\
\hline Yes (\%) & $25(36.8)$ & $27(40.9)$ & 0.6 \\
\hline Enrollment delay: mean (hours) & 17.3 & 19.9 & 0.4 \\
\hline \multicolumn{4}{|l|}{ Injured ankle periarticular edema (mm) } \\
\hline Mean (SD) & $254(27)$ & $253(29)$ & \\
\hline Median (minimum-maximum) & $256(150-300)$ & $260(127-302)$ & 0.9 \\
\hline \multicolumn{4}{|l|}{ VAS self-evaluation (patient) } \\
\hline Mean (SD) & $66.9(10.6)$ & $70.0(11.8)$ & \\
\hline Median (minimum-maximum) & $66.0(50-92)$ & $67.5(50-100)$ & 0.2 \\
\hline \multicolumn{4}{|l|}{ Pain at rest (clinician) } \\
\hline None/low/moderate/high & $10 / 32 / 24 / 2$ & $\mathrm{I} \mathrm{I} / 28 / 23 / 4$ & 0.8 \\
\hline \multicolumn{4}{|l|}{ Pain on passive stretch (clinician) } \\
\hline None/low/moderate/high & $0 / 4 / 36 / 28$ & $0 / 4 / 29 / 33$ & 0.4 \\
\hline \multicolumn{4}{|l|}{ Pain on palpation (clinician) } \\
\hline None/low/moderate/high & $0 / 0 / 23 / 45$ & $0 / 2 / 21 / 43$ & 0.7 \\
\hline \multicolumn{4}{|l|}{ Single foot leaning (patient) } \\
\hline Okay without pain/okay with pain/impossible & $4 / 52 / 12$ & $6 / 44 / 16$ & 0.5 \\
\hline
\end{tabular}

Note: 'Fisher's exact test of heterogeneity for dichotomous variables and Wilcoxon nonparametric test for quantitative variables.

Abbreviations: DETP, diclofenac epolamine topical patch; n, number of patients; SD, standard deviation; VAS, visual analog scale.

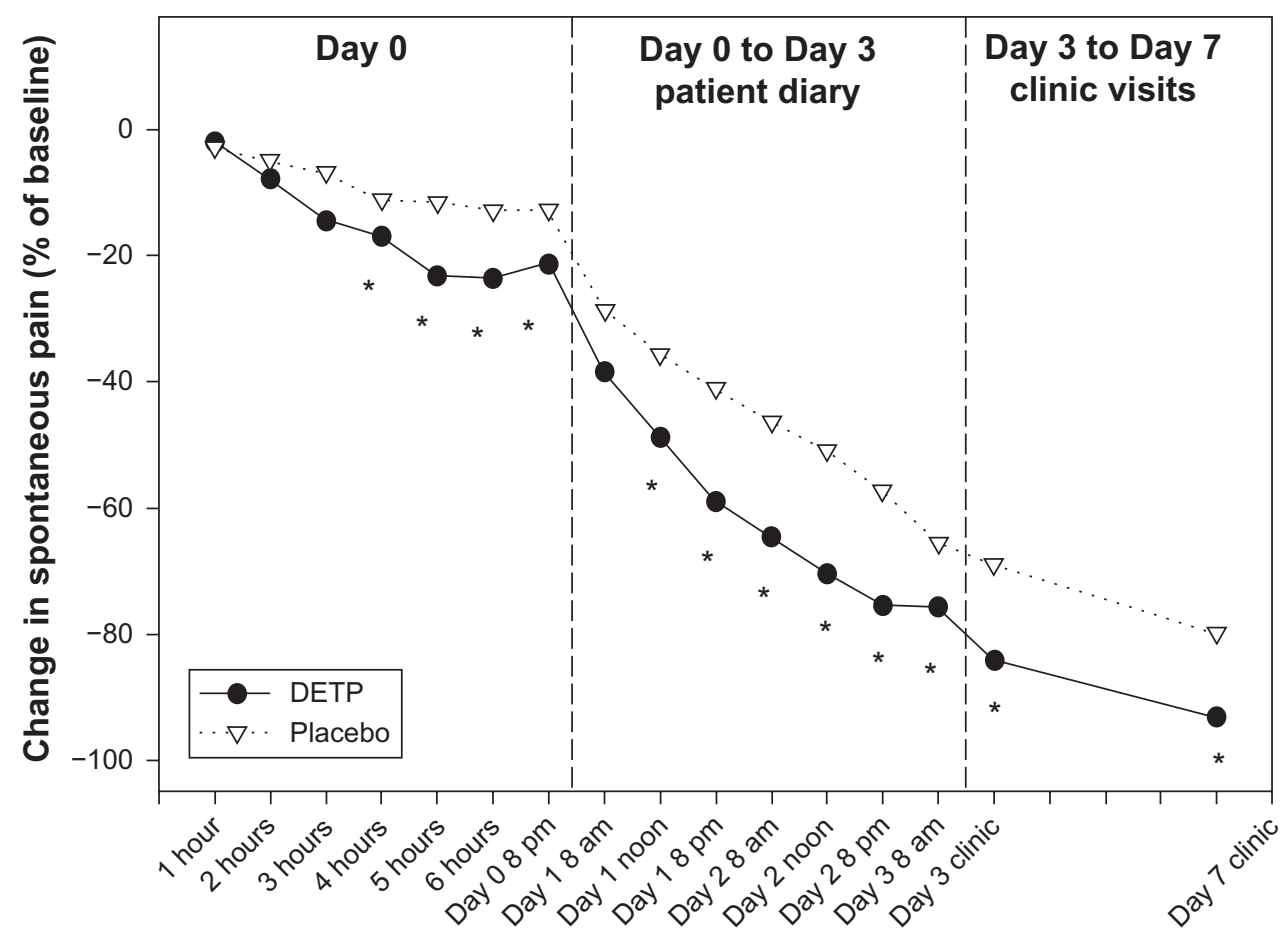

Figure I Change in spontaneous pain, as measured by VAS, median percent change from baseline.

Note: *Denotes statistically significant difference.

Abbreviations: DETP, diclofenac epolamine topical patch; VAS, visual analog scale. 
analog score (expressed as percent of baseline) and defined as (minimally) a 30\% reduction in pain, the success rate was significantly higher in the DETP group from four hours after the first application (36.8\% DETP versus $16.7 \%$ placebo, $P=0.01, \mathrm{n}=134$ ), and remained significant for seven of the 10 measures until day 2 at the 8 pm time point.

The secondary efficacy measures of pain at rest, on passive stretch, on palpation, and possibility of foot leaning were similar between the two groups on day 0 . In contrast, on day 3 and day 7, the DETP group showed a favorable response in analgesic effect that was statistically significant compared with the placebo group in each of the four analgesic efficacy measures (Table 2). Perimalleolar edema values did not show any significant difference between the treatment groups throughout the study.

\section{Tolerability}

The DETP and placebo patch were equally well tolerated on both day 3 and day 7, indicating consistent tolerance over time. No statistically significant difference was observed between the DETP and placebo with either patient or physician assessment of tolerability on day 3 or day 7 . The overall incidence of adverse events was comparable between the DETP and placebo groups. Two (3\%) patients in the DETP and three (4.5\%) patients in the placebo group reported an adverse event (Table 3 ). In both groups, adverse events were of mild to moderate severity and generally involved the skin.

\section{Discussion}

The purpose of this study was to assess the analgesic efficacy of the DETP in acute ankle injury. It is apparent from the efficacy data presented in this study that patients treated with the DETP experienced a significantly greater reduction in pain associated with their ankle injury, determined from visual analog scale scores, beginning four hours after the first patch application and lasting (except for a single time point) for the remainder of the seven-day treatment period. In addition, patients in the DETP treatment group experienced reduced pain at rest, on passive stretch, palpitation,

Table 2 Analgesic effect results

\begin{tabular}{|c|c|c|c|}
\hline & $\begin{array}{l}\text { DETP } \\
(n=68)\end{array}$ & $\begin{array}{l}\text { Placebo } \\
(n=66)\end{array}$ & $P$ value \\
\hline \multicolumn{4}{|l|}{ Pain at rest } \\
\hline \multicolumn{4}{|l|}{ Day 0} \\
\hline None/low/moderate/high & $10 / 32 / 24 / 2$ & $\mathrm{II} / 28 / 23 / 4$ & 0.8 \\
\hline \multicolumn{4}{|l|}{ Day 3} \\
\hline None/low/moderate/high & $49 / 18 / 1 / 0$ & $33 / 25 / 8 / 0$ & $0.002 *$ \\
\hline \multicolumn{4}{|l|}{ Day 7} \\
\hline None/low/moderate/high & $60 / 8 / 0 / 0$ & $41 / 19 / 6 / 0$ & $0.00 I^{*}$ \\
\hline \multicolumn{4}{|l|}{ Pain on passive stretch } \\
\hline \multicolumn{4}{|l|}{ Day 0} \\
\hline None/low/moderate/high & $0 / 4 / 36 / 28$ & $0 / 4 / 29 / 33$ & 0.4 \\
\hline \multicolumn{4}{|l|}{ Day 3} \\
\hline None/low/moderate/high & $12 / 34 / 20 / 2$ & $4 / 26 / 30 / 6$ & $0.003^{*}$ \\
\hline \multicolumn{4}{|l|}{ Day 7} \\
\hline None/low/moderate/high & $30 / 29 / 7 / 2$ & $17 / 22 / 23 / 4$ & $0.00 I^{*}$ \\
\hline \multicolumn{4}{|l|}{ Pain on palpation (\%) } \\
\hline \multicolumn{4}{|l|}{ Day 0} \\
\hline None/low/moderate/high & $0 / 0 / 23 / 45$ & $0 / 2 / 2 I / 43$ & 0.7 \\
\hline \multicolumn{4}{|l|}{ Day 3} \\
\hline None/low/moderate/high & $7 / 28 / 25 / 8$ & $2 / 19 / 29 / 16$ & $0.007^{*}$ \\
\hline \multicolumn{4}{|l|}{ Day 7} \\
\hline None/low/moderate/high & $20 / 33 / 12 / 3$ & $8 / 25 / 20 / 13$ & $0.001 *$ \\
\hline \multicolumn{4}{|l|}{ Possibility of single foot leaning } \\
\hline \multicolumn{4}{|l|}{ Day 0} \\
\hline Okay without pain/okay with pain/impossible & $4 / 52 / 12$ & $6 / 44 / 16$ & 0.7 \\
\hline \multicolumn{4}{|l|}{ Day 3} \\
\hline Okay without pain/okay with pain/impossible & $36 / 31 / 1$ & $23 / 37 / 6$ & $0.002 *$ \\
\hline \multicolumn{4}{|l|}{ Day 7} \\
\hline Okay without pain/okay with pain/impossible & $56 / 11 / 1$ & $37 / 28 / 1$ & $0.00 I^{*}$ \\
\hline
\end{tabular}

Note: *Denotes statistically significant difference.

Abbreviations: DETP, diclofenac epolamine topical patch; $n$, number of patients. 
Table 3 Summary of adverse events

\begin{tabular}{lcc}
\hline & $\begin{array}{l}\text { DETP } \\
(\mathbf{n}=68)\end{array}$ & $\begin{array}{l}\text { Placebo } \\
\mathbf{( n = 6 6 )}\end{array}$ \\
\hline $\begin{array}{l}\text { Adverse events, n (\%) } \\
\text { Skin }\end{array}$ & $2(3.0 \%)$ & $3(4.5 \%)$ \\
$\quad \begin{array}{l}\text { Pruritus } \\
\quad \text { Other (application site burning) }\end{array}$ & $\mathrm{I}(1.5 \%)$ & $2^{\mathrm{a}}(3.0 \%)$ \\
Body as a whole & $0(0.0 \%)$ & $\mathrm{I}(1.5 \%)$ \\
$\quad$ Allergic reaction & $\mathrm{I}(\mathrm{I} .5 \%)$ & $0(0.0 \%)$ \\
\hline
\end{tabular}

Note: a One event led to discontinuation of the study treatment.

Abbreviations: DETP, diclofenac epolamine topical patch; $n$, number of patients.

and the possibility of single foot leaning on day 3 and day 7 . The demonstrated benefits of topical therapy suggest that the origins of ankle pain in this case were primarily local. For patients who do not respond to local therapy, distant trigger points or other remote origins of pain should be considered.

No gastrointestinal-related adverse events were reported in this study. Analyses of safety data from this study are consistent with prior experience, with only five patients reporting adverse events of mild to moderate severity (four involving skin), and most of the patients in either treatment group having good/excellent product tolerability as judged by both the patient and investigator. ${ }^{8}$ An acknowledged shortcoming of this trial is that the comparison with placebo, which facilitated identification of treatment-related adverse events, precluded the use of an active analgesic comparator. Additional studies should include comparison with other active analgesics.

By comparison, in both seven-day and 14-day studies involving the DETP for the treatment of acute pain, the incidence of adverse events related to the gastrointestinal system was similar for both the DETP-treated and placebotreated patients $(0 \%-10 \%){ }^{8-10}$ In contrast, studies comparing celecoxib with naproxen or ibuprofen for the management of acute pain reported gastrointestinal-related adverse events in up to $20 \%$ of patients in the celecoxib group and $25 \%$ of patients in the naproxen group. ${ }^{12,13}$

Additional topical products approved in the US at this time include the lidocaine patch $5 \%$, diclofenac sodium topical gel $1 \%$, and diclofenac sodium topical solution $1.5 \%$. Significant improvements compared with baseline were seen for the lidocaine patch in several studies of osteoarthritis and low back pain. ${ }^{14-16}$ Because all of these studies were open label, the results should be interpreted with caution. The diclofenac sodium gel $1 \%$ is a prescribed topical gel that can be applied directly for osteoarthritis pain of the knee and hand, producing efficacious pain reduction. ${ }^{17,18}$ However, a study comparing diclofenac gel and a ketoprofen patch in sports-related soft tissue injuries revealed that patients preferred the patch application to the gel despite equivalent pain reduction. ${ }^{19}$

\section{Conclusion}

This study assessed the superior analgesic efficacy of the DETP compared with placebo in minor sports injuries with a four-hour onset, while maintaining superior pain relief for the treatment duration. The DETP affords localized NSAID treatment, thereby minimizing systemic drug exposure. Therefore, the DETP has an important role as an alternative to traditional oral NSAIDs in the treatment of these injuries, without the adverse event profile of the oral agents.

\section{Disclosures}

DRL is a paid consultant for King Pharmaceuticals ${ }^{\circledR}$, Inc, and has received honoraria in the past 18 months. At the time of this work, JY and MM were employees of Alpharma Pharmaceuticals, LLC, a wholly owned subsidiary of King Pharmaceuticals ${ }^{\circledR}$, Inc, which markets the DETP. AL is an employee of the Institut Biochimique SA which sponsored the DETP studies described herein. Writing and editorial assistance for this article was provided by MMS Holdings, Canton, MI, USA and Quintiles Medical Communications, Parsippany, NJ, USA. Funding for writing and editorial support was provided by Alpharma Pharmaceuticals, LLC, a wholly owned subsidiary of King Pharmaceuticals ${ }^{\circledR}$, Inc., Bristol, TN, USA.

\section{References}

1. Ivins D. Acute ankle sprain: An update. Am Fam Physician. 2006; 74(10):1714-1720

2. Wolfe MW, Uhl TL, Mattacola CG, McCluskey LC. Management of ankle sprains. Am Fam Physician. 2001;63(1):93-104.

3. Green GA. Understanding NSAIDs: From aspirin to COX-2. Clin Cornerstone. 2001;3(5):50-60.

4. Weaver AL. Current and emerging treatments for mild/moderate acute ambulatory pain. Am J Ther. 2008;15 Suppl 10:S12-6.

5. Flector Patch (diclofenac epolamine topical patch) $1.3 \%$ full prescribing information (United States). Piscataway, NJ: Alpharma Pharmaceuticals, LLC; 2009.

6. Petersen B, Rovati S. Diclofenac epolamine (Flector) patch: Evidence for topical activity. Clin Drug Investig. 2009;29(1):1-9.

7. Gallacchi G, Marcolongo R. Pharmacokinetics of diclofenac hydroxyethylpyrrolidine (DHEP) plasters in patients with monolateral knee joint effusion. Drugs Exp Clin Res. 1993;19(3):95-97.

8. Galer BS, Rowbotham M, Perander J, Devers A, Friedman E. Topical diclofenac patch relieves minor sports injury pain: Results of a multicenter controlled clinical trial. J Pain Symptom Manage. 2000;19(4): 287-294

9. Rowbotham MC, Galer BS, Block JA, Backonja MM. Flector Tissugel ${ }^{\circledR}$ : Efficacy and safety in the treatment of minor sports injuries. Data from a controlled trial in the United States. J Traumatol Sport. 2003;20:1S151S20. French. 
10. Saillant G. Study comparing the efficacy and tolerance of Flector Tissuge ${ }^{\circledR}$ to that of a placebo in the treatment of benign ankle sprains. Medicine du Sport. 1998;72:1-5. French.

11. Farrar JT, Berlin JA, Strom BL. Clinically important changes in acute pain outcome measures: A validation study. J Pain Symptom Manage. 2003;25(5):406-411.

12. Bertin P, Béhier JM, Noël E, Leroux JL. Celecoxib is as efficacious as naproxen in the management of acute shoulder pain. $J$ Int Med Res. 2003;31(2):102-112.

13. Petrella R, Ekman EF, Schuller R, Fort JG. Efficacy of celecoxib, a COX-2-specific inhibitor, and naproxen in the management of acute ankle sprain: Results of a double-blind, randomized controlled trial. Clin J Sport Med. 2004;14(4):225-231.

14. Burch F, Codding C, Patel N, Sheldon E. Lidocaine patch $5 \%$ improves pain, stiffness, and physical function in osteoarthritis pain patients. A prospective, multicenter, open-label effectiveness trial. Osteoarthritis Cartilage. 2004;12(3):253-255.

15. Galer BS, Sheldon E, Patel N, Codding C, Burch F, Gammaitoni AR. Topical lidocaine patch 5\% may target a novel underlying pain mechanism in osteoarthritis. Curr Med Res Opin. 2004;20(9): 1455-1458.
16. Gimbel J, Linn R, Hale M, Nicholson B. Lidocaine patch treatment in patients with low back pain: Results of an open-label, nonrandomized pilot study. Am J Ther. 2005;12(4):311-319.

17. Altman RD, Dreiser RL, Fisher CL, Chase WF, Dreher DS, Zacher J. Diclofenac sodium gel in patients with primary hand osteoarthritis: A randomized, double-blind, placebo-controlled trial. J Rheumatol. 2009;36(9):1991-1999.

18. Barthel HR, Haselwood D, Longley S 3rd, Gold MS, Altman RD. Randomized controlled trial of diclofenac sodium gel in knee osteoarthritis. Semin Arthritis Rheum. 2009;39(3):203-212.

19. Esparza F, Cobián C, Jiménez JF, García-Cota JJ, Sanchez C, Máestro A Topical ketoprofen TDS patch versus diclofenac gel: Efficacy and tolerability in benign sport related soft-tissue injuries. Br J Sports Med. 2007;41(3):134-139.
Journal of Pain Research

\section{Publish your work in this journal}

The Journal of Pain Research is an international, peer-reviewed, open access, online journal that welcomes laboratory and clinical findings in the fields of pain research and the prevention and management of pain. Original research, reviews, symposium reports, hypothesis formation and commentaries are all considered for publication.

\section{Dovepress}

The manuscript management system is completely online and includes a very quick and fair peer-review system, which is all easy to use. Visit http://www.dovepress.com/testimonials.php to read real quotes from published authors. 